\title{
Screening of Prostate Cancer by Prostate Specific Antigen and its Prevalence in Jammu Region
}

RACHNA SABHARWAL, AMARJEET S. BHATIA, LAKHBIR SINGH

\section{ABSTRACT}

Introduction: Prostate cancer is most commonly diagnosed non-cutaneous cancer in men. Prostate specific antigen is the biomarker used for screening of prostate cancer and prostate related problems. Not only the genetic factors are involved, dietary factors and environmental factors are also responsible for the development of prostate cancer. Risk factors like family history, age, chemical exposure, infection and smoking are at the peak point for the development of prostatic disease. Advanced age is one of the main risk factor. Most commonly prostate abnormalities are seen among male patients of 50 years and above. Early screening using PSA reduces the incidence rate of prostate cancer.

Aim: Aim of our study is to use PSA as biomarker to screen male population for prostate related problems, to compare its levels in smokers and non smokers and to detect the prevalence of prostate cancer in Jammu region.

Materials and Methods: The study was conducted in department of Biochemistry, Super speciality hospital, Government Medical College Jammu. $3 \mathrm{ml}$ blood sample was collected from antecubital vein under aseptic precautions in a plain vacutainer and incubated at room temperature; serum was separated by centrifuge machine at $2000 \mathrm{rpm}$ for 5 minutes. The samples were analyzed by Abott Architect Auto analyser using Chemiluminescent Microparticle Immunoaasay (CMIA). A total 150 males of age 50 years and above who had prostate related problems were screened using PSA as biomarker.

Results: Our study showed that the mean PSA levels in normal persons were $2.59 \mathrm{ng} / \mathrm{dl}$ whereas in patients with $\mathrm{BPH}$ the mean levels were comparatively high i.e. $6.89 \mathrm{ng} /$ $\mathrm{dl}$ and were very high in patients with prostate cancer i.e. $21.18 \mathrm{ng} / \mathrm{dl}$. Similarly, the mean levels of PSA in smokers were comparatively high $(12.13 \mathrm{ng} / \mathrm{dl})$ as compared to nonsmokers $(10.18 \mathrm{ng} / \mathrm{dl})$ Prevalence of prostate cancer cases in Jammu district was estimated to be $15 \%$ per year.

Conclusion: Screening of men for prostatic problems by using PSA is helpful in early detection of prostate cancer. There is a significant association between smoking and PSA levels.

Keywords: Benign prostatic hyperplasia (BPH), Chemiluminiscent Microparticle Immunoassay (CMIA), Digital Rectal Examination (DRE).

\section{INTRODUCTION}

Prostate specific antigen, a glycoprotein having 237 amino acids is a serine protease exclusively secreted by prostatic epithelial cells. Serum contains PSA, the levels of which can be measured reliably by either a monoclonal immunometric assay or a polyclonal radioimmunoassay [1]. Half-life of serum PSA ranges from 2.2 to 3.2 days and its metabolic clearance follows first-order kinetics. False or spurious elevation of serum PSA levels can occur with digital rectal examination, cystoscopic examination, prostate biopsy and in conditions like bacterial prostatitis and acute urinary retention. Around $30-50 \%$ of patients with $\mathrm{BPH}$ have elevated serum PSA levels, depending on the size of the prostate and the degree of obstruction, and the concentrations are increased in 25$92 \%$ of patients with prostatic cancer, depending on tumor volume. The clinical staging of prostatic cancer can not be determined reliably by PSA concentration even though there is a direct correlation between the serum PSA levels and clinical stage. Prostate cancer is second most common cancer and third most common cause of death in men due to cancers in developed countries. In 1982, PSA was used to describe as prostate cancer marker, its first screening report came into existence in 1991 [2].

In Western countries, the factors like diet and obesity may be positively associated with etiology of prostate cancer leading to excess risk of this cancer in these countries. A complex interplay of risk factors like genetic, environmental or lifestyle may be associated with prostatic cancer development [3]. The high grades of PSA levels are found in 50 years of age or in older males. Measurement of serum PSA is the most specific marker for monitoring the progression of prostate cancer and response to therapy. It offers several advantages over rectal examination or transrectal prostatic ultrasonography in screening for prostate cancer [4]. 


\section{AlM}

1) To screen male population of age 50 years or older for prostate related problems by using PSA as biomarker.

2) To compare PSA levels between smokers and nonsmokers.

3) To detect the prevalence of prostate cancer in Jammu region.

\section{MATERIALS AND METHODS}

It is a prospective cross-sectional study conducted in Department of Biochemistry, Super Speciality Hospital, Government Medical College Jammu from August 2014 to September 2015. The consent of institutional ethical committee was obtained. Convenient sampling was done. Total 150 male patients of age 50 years and above who visited the OPD were screened for prostate related problems using PSA.

Known patients of prostate cancer and subjects with previous prostatic or urethral surgery were excluded from the study. Subjects who had UTI, urethral catheters and sexual relationship in last 24 hours were also excluded from the study. Personal history was obtained from all the subjects and most of them were smokers or ex-smokers. A total of $3 \mathrm{ml}$ blood sample was collected from antecubital vein under aseptic precautions in a plain vacutainer and incubated at room temperature, serum was separated by centrifugation at $2000 \mathrm{rpm}$ for five minutes. The samples were analyzed using Abott Architect Autoanalyser.

PSA testing was done in conjunction with DRE in all the subjects. Patients with significantly high levels of PSA were followed further for their biopsy reports.

Method- ARCHITECT total PSA by Chemiluminescent Microparticle Immunoaasay (CMIA).

It involves 2 steps: In first step sample is combined with anti-PSA coated paramagnetic micro particles. PSA present in the sample binds to anti-PSA coated microparticles. In second step anti-PSA accredinium labelled conjugate is added followed by addition of pre trigger and trigger solutions to the reaction mixture, the resultant chemiluminescent is measured as reactive light units. A direct relationship is seen between the levels of total PSA in the sample and reactive light units detected.

\section{RESULTS}

A prospective study was conducted to demonstrate the usefulness of PSA for detection of prostate cancer. A total 150 men of age 50 years or above participated in the study. Following observations were made from the study conducted by us: [Table/Fig-1] shows, the mean levels of PSA in normal, $\mathrm{BPH}$ and prostate cancer patients. It reveals that out of 150 patients 80 had normal levels, 60 had comparatively high levels and were diagnosed as BPH whereas, 10 had significantly high levels of PSA and were diagnosed as prostate cancer after histopathology of prostate biopsy. [Table/Fig-2] shows, the mean levels of PSA in smokers and non smokers. Out of 150 patients 70 were smokers who

\begin{tabular}{|l|c|}
\hline Category 1 & PSA (ng/dl) \\
\hline Normal $(n=80)$ & 2.59 \\
\hline BPH $(n=60)$ & 6.89 \\
\hline Malignant $(n=10)$ & 21.18 \\
\hline \multicolumn{2}{|l|}{ [Table/Fig-1]: Level of PSA in normal, BPH and cancer patients. }
\end{tabular}

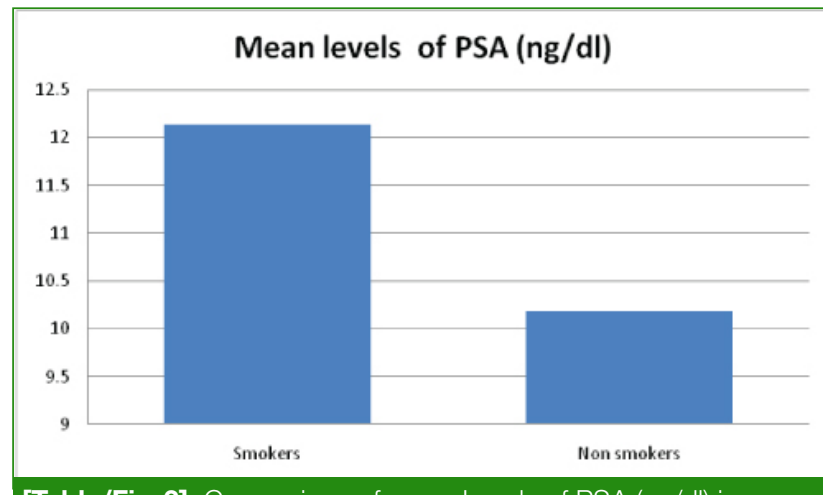

[Table/Fig-2]: Comparison of mean Levels of PSA (ng/dl) in smokers and non smokers.

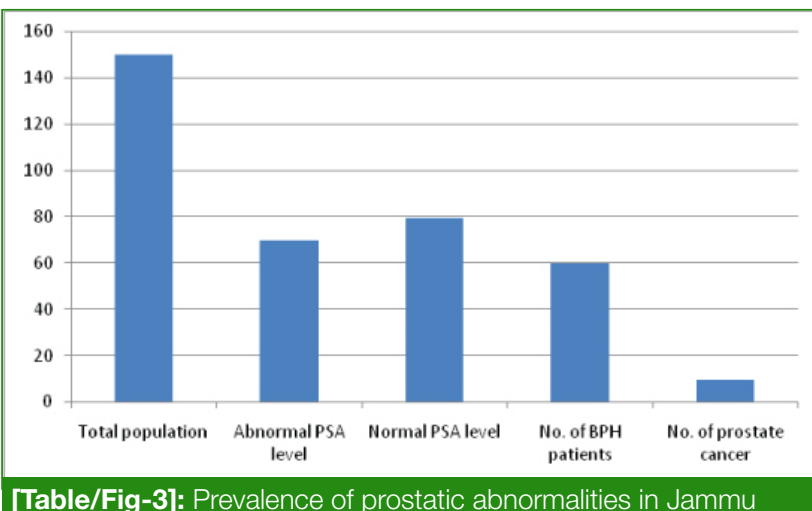

[Table/Fig-3]: Prevalence of prostatic abnormalities in Jammu region.

showed comparatively higher levels of PSA $(12.13 \mathrm{ng} / \mathrm{dl})$ as compared to non-smokers $(10.18 \mathrm{ng} / \mathrm{dl})$.

[Table/Fig-3] shows, prevalence of prostatic abnormalities in Jammu region. Out of 70 patients with abnormal PSA levels 60 were diagnosed to have $\mathrm{BPH}$ and 10 had prostate cancer.

\section{DISCUSSION}

PSA is a serine protease with chymotrypsin-like activity. It belongs to human kallikrein gene family, excreted mainly by the glandular epithelium of the prostate gland [5]. Physiologically, it is present in the seminal fluid at high concentration $(0.5-2.0 \mathrm{mg} / \mathrm{ml})$ and functions to cleave the high molecular weight protein responsible for the seminal coagulum into smaller polypeptides. This action results in liquefaction of the coagulum [1].

Blood concentration of PSA is 1000 times less as compared to seminal fluid. The changes in concentration are independent of other proteins; its change depends upon 
serum testosterone levels [6]. High levels of PSA occur in prostatic pathology including prostatitis, benign prostatic hypertrophy and prostatic cancer $[7,4]$.

Most prostate tumours have multiple neoplastic foci leading to their heterogenous nature [8]. Development and progression of prostatic cancers is a multistep process. Malignant cells develop due to genetic alterations. Prostatic intraepithelial neoplasia and premalignant lesions are considered as intermediary phase from benign epithelium to carcinoma.

$\mathrm{BPH}$ is a condition in which the prostate gland becomes enlarged due to the overgrowth of epithelial nodules and stroma tissue in the transition zone of the prostate, the symptoms are similar to that of prostate cancer especially in elderly age group [9]. By the advanced age of men, testosterone concentration becomes lower and estrogen concentration becomes high in blood. According to studies, higher concentration of estrogen increases the smooth muscle cell proliferation and differentiation, this may lead to $\mathrm{BPH}[10]$.

In our study 150 men were screened for PSA levels, out of which 70 were found to have high levels. Out of the men having high PSA levels, 60 were diagnosed to have benign prostatic hypertrophy and 10 were found to be positive for prostate cancer which was confirmed by histopathology.

The mean PSA levels in normal persons were 2.59ng/dl whereas, the mean PSA levels in patients with benign prostatic hypertrophy were $6.89 \mathrm{ng} / \mathrm{dl}$ which were comparatively higher than the normal range. However, in person with malignancy, significantly high levels of PSA (21.18 ng/dl)were found. Our results were comparable with other studies conducted by William et al., [2] and Cooner et al., [11] who also have observed that PSA is a useful screening test for detection of prostate cancers.

Comparative analysis of PSA was done in smokers and non-smokers also. Out of 150 men screened for PSA, 70 had the history of smoking. There is a significant association of smoking with PSA levels. The levels of PSA were high in smokers as compared to non-smokers which were also comparable with other studies conducted by Algotar et al., [12] and Gokhan et al., [13] who also observed higher PSA levels in smokers compared to non smokers. Our findings were also supported by study of Giovannucci et al., [14] who observed that lifetime smoking was a risk factor for development of prostatic carcinoma.

Gray et al., [15] in their study have observed significantly lower levels of free PSA and free PSA\% values in smokers than in non smokers but such difference was not shown with regard to total PSA values. Kristal et al., [16] and Gelmann et al., [17] have also revealed lower levels of PSA in smokers than in non smokers. However, the underlying cause for low PSA levels was not clearly explained. Later on, Li et al., [18] have observed significantly lower PSA levels in smokers than in non-smokers, which according to their study was due to increased levels of Sex Hormone Binding Globulin (SHBG).
On the contrary we observed that PSA levels were higher in smokers as compared to non smokers.

Smoking is the causative factor for many neoplasms. It leads to endocrine disturbances which change levels of PSA. Increased circulating levels of testosterone, androstenedione, and dihydrotestosterone are seen in male smokers as compared to non-smokers. Testosterone stimulates the prostatic epithelial cells to secrete the PSA. In addition, $\alpha-1$ antitrypsin, which is a plasma protein synthesized in the liver, inhibits serine proteases. Cigarette smoking causes deficiency of $\alpha-1$ antitrypsin thus leading to increased levels of PSA, which is a serine protease [19].

Many cross-sectional studies have shown that carcinogenic compounds in the cigarettes, such as polycyclic aromatic hydrocarbons, heterocyclic aromatic amines, and nitrosamines are responsible for carcinogenesis in the prostate. Few studies have also shown that low levels of insulin-like growth factor (IGF)-I and IGF binding protein-3 (IGFBP-3) in serumarepositively associated with prostatic neoplasms [7].

\section{LIMITATION}

It was a convenience study i.e. the patients coming to OPD for prostate related problems were analysed for PSA levels and randomization could not be done. Our study is also limited by small number of subjects, thus further prospective randomized studies with more number of patients are required.

\section{CONCLUSION}

It was concluded from the present study that prostate cancer is a major health problem. Early and routine screening for prostate disorders by PSA in conjunction with DRE above the age of 50 years identifies patients at high risk, makes management easy and lowers the impact of disease as well as mortality by prostatic cancers. We also observed in our study that levels of PSA were higher in smokers as compared to non-smokers. The prevalence of prostate cancer in the studied population was $15 \%$. It is hoped that this work would help alert the adult male population on the need to go for early and routine screening for prostate disorders.

\section{REFERENCES}

[1] Oesterling JE. Prostate specific antigen: a critical assessment of the most useful tumor marker for adenocarcinoma of the prostate. J Urol. 1991;145(5):907-23.

[2] Catalona WJ, Smith DS, Ratliff TL, Dodds KM, Coplen DE, Yuan JJ, et al. Measurement of prostate specific antigen in serum as a screening test for prostate cancer. $N$ Engl $J$ Med. 1991;324(17);1156-61.

[3] Parkin DM, Pisani P and Ferlay J. Global cancer statistics. CA cancer. J Clin.1999;49; 33-64.

[4] Partin AW, Oesterling JE. The clinical usefulness of prostate specific antigen: update 1994. J Urol. 1994; 152(5 Pt 1):1358-68.

[5] McCormack RT, Rittenhouse HG, Finlay JA, Sokoloff RL, Wang $T J$, Wolfert RL, et al. Molecular forms of prostate-specific antigen and the human kallikrein gene family: a new era. Urology. 1995; 45(5):729-44. 
[6] Guess HA, Gormley GJ, Stoner E, Oesterling JET. The effect of finasteride on prostate specific antigen: review of available data. J Urol. 1996;155:3-9.

[7] Chan JM, Stampfer MJ, Giovannucci E, Gann PH, Ma J, Wilkinson P, et al. Plasma insulin-like growth factor-I and prostate cancer risk: a prospective study. Science. 1998;279(5350):56366.

[8] Jácome-Pita FX, Sánchez-Salas R, Barret E, Amaruch N, Gonzalez-Enguita C, and Cathelineau X. Focal therapy in prostate cancer: the current situation. E cancer medical science. 2014; 8: 435.

[9] Bostwick DG, Cooner WH, Denis L, Jones GW, Scardino PT, Murphy GP. The association of benign prostatic hyperplasiaandcancer of theprostate. Cancer. 1992;70(1 Suppl):291-301.

[10] Zhang J, Hess MW, Thurnher M, HobischA, Radmayr C, Cronauer MV, et al. Human prostatic smooth muscle cells in culture: estradiol enhances expression of smooth muscle cellspecific markers. Prostate. 1997;30(2):117-29.

[11] Cooner WH, Mosley BR, Rutherford CL Junior. Prostate cancer detection in a clinical urological practice by ultrasonography, digital rectal examination and prostate specific antigen. $J$ urol 1990; 143:1146-52.

[12] Algotar AM, Stratton SP, Moore JR, Stratton MS, Hsu CH, Ahmann FR, et al. Association of obesity and smoking with PSA and PSA velocity in men with prostate cancer. Am J Mens Health. 2011; 5(3): 272-78.
[13] Gokhan K, Korhan A, Yuksel Y, Alper D, Sitki U. The effects of cigarette smoking on prostate-specific antigen in two different age groups. Can Urol Assoc J. 2013; 7(11-12): E704-07.

[14] Giovannucci E, Liu Y, Platz EA, Stampfer MJ, Willett WC. Risk factors for prostate cancer incidence and progression in the health professionals' follow-up study. International Journal of Cancer. 2007;121:1571-78.

[15] Gray MA, Delahunt B, Fowles JR, Weinstein P, Cookes RR, Nancy JET. Demographic and clinical factors as determinants of serum levels of prostate specific antigen and its derivatives. Anticancer Res. 2004;24:2069-72.

[16] Kristal AR, Chi C, Tangen CM, Goodman PJ, Etzioni R, Thompson IM. Associations of demographic and lifestyle characteristics with prostate-specific antigen (PSA) concentration and rate of PSA increase. Cancer. 2006;106:320-28.

[17] Gelmann EP, Chia D, Pinsky PF, Andriole GL, Crawford ED. PLCO screening trial investigators relationship of demographic and clinical factors to free and total prostate-specific antigen. Urology. 2001;58:561-66.

[18] Li J, Thompson T, Joseph DA, Master VA. Association between smoking status, and free, total and percent free prostate specific antigen. J Urol. 2012;187:1228-33.

[19] Kalsheker NA. a1-Antitrypsin deficiency: best clinical practice. J Clin Pathol. 2009;62:865-69.

\section{AUTHOR(S):}

1. Dr. Rachna Sabharwal

2. Dr. Amarjeet S. Bhatia

3. Mr. Lakhbir Singh

\section{PARTICULARS OF CONTRIBUTORS:}

1. Lecturer, Department of Biochemistry, Government Medical College, Jammu, Jammu and Kashmir, India.

2. Associate Professor, Department of Biochemistry, Government Medical College, Jammu, Jammu and Kashmir, India.
3. Lecturer, Department of Biochemistry, Government Medical College, Jammu, Jammu and Kashmir, India.

\section{NAME, ADDRESS, E-MAIL ID OF THE CORRESPONDING AUTHOR:}

Dr. Rachna Sabharwal,

Department of Biochemistry, Government Medical College, Jammu, Jammu and Kashmir-180001, India.

E-mail: rachnamahajan71@yahoo.com

\section{FINANCIAL OR OTHER COMPETING INTERESTS:}

None. 